\title{
Genetic Variability and Inter-relationship of Kernel Carotenoids among Indigenous and Exotic Maize (Zea mays L.) Inbreds
}

\author{
V. Muthusamy ${ }^{1}$, F. Hossain $^{1}$, N. ThirunavukKarasu ${ }^{1}$, S. Saha ${ }^{1}$, P.K. Agrawal ${ }^{2}$, \\ S.K. GULERIA ${ }^{3}$ and H.S. GUPTA ${ }^{1,4 *}$ \\ ${ }^{1}$ ICAR-Indian Agricultural Research Institute (IARI), New Delhi, India \\ ${ }^{2}$ ICAR-Vivekananda Parvatiya Krishi Anusandhan Sansthan (VPKAS), Almora, India \\ ${ }^{3}$ C.S.K. Himachal Pradesh Krishi Viswavidyalaya (CSK-HPKV), Bajaura Centre, India \\ ${ }^{4}$ Borlaug Institute for South Asia (BISA), New Delhi, India
}

(Received 26 August 2014; Accepted 3 December 2014; Communicated by H. Grausgruber)

\begin{abstract}
Carotenoids play vital role in growth and development of human beings. Yellow maize kernel contains carotenoids that possess provitamin A and antioxidant activity. Multilocation based analyses of 105 maize inbreds of indigenous and exotic origin revealed wide genetic variation for lutein $(0.2-11.3 \mu \mathrm{g} / \mathrm{g})$, zeaxanthin $(0.2-20.0 \mu \mathrm{g} / \mathrm{g})$ and $\beta$-carotene $(0.0-15.0 \mu \mathrm{g} / \mathrm{g})$. For $\beta$-cryptoxanthin, low variation $(0.1-3.3 \mu \mathrm{g} / \mathrm{g})$ was observed. Carotenoids were quite stable over environments that played minor role in causing variation. The heritability $(>90 \%)$ and genetic advance $(>75 \%)$ were high for all the carotenoid components. Zeaxanthin showed positive correlation with lutein and $\beta$-cryptoxanthin, while $\beta$-carotene, the major provitamin A carotenoid, did not show correlation with other carotenoids. Kernel colour was positively correlated with lutein $(0.25)$, zeaxanthin $(0.47)$ and $\beta$-cryptoxanthin $(0.44)$, but not with $\beta$-carotene (0.04). This suggested that visual selection based on kernel colour will be misleading in selecting provitamin A-rich genotypes. Inbreds with provitamin A and non-provitamin A carotenoids identified in the present study will help in development of biofortified maize hybrids.
\end{abstract}

Keywords: maize, carotenoids, variability, provitamin A, antioxidants

\section{Introduction}

Carotenoids are lipid soluble polyenes and are abundantly found in plant systems (Howitt and Pogson 2006). In plants, carotenoids prevent chlorophyll from photo-oxidative damage and protect membranes from lipid peroxidation. They serve as precursors to abscisic acid (ABA), which regulates plant growth, embryo development, dormancy, and stress responses (Nambara and Marion-Poll 2005; Johnson et al. 2007). However, the presence of carotenoids in the diet adds nutritional value; and it provides micronutrients that are required for proper growth and development in humans. Among carotenoids, $\alpha$-carotene,

\footnotetext{
* Corresponding author; E-mail: hsgupta.53@gmail.com
} 
$\beta$-carotene and $\beta$-cryptoxanthin are provitamin A carotenoids that are hydrolyzed in the intestinal mucosa to liberate retinol or vitamin $\mathrm{A}$, an essential micronutrient required for vision in humans (Hess et al. 2005). Besides, non-provitamin A carotenoids viz. lutein and zeaxanthin act as antioxidants and are associated with decreased risk of several degenerative diseases in humans, particularly cardiovascular disease, cancer and macular degeneration (Fraser and Bramley 2004). The efforts thus directed to increase provitamin A and non-provitamin A carotenoids in maize will have positive impact on the health and well-being of humans, especially women and children.

Maize serves as staple food for more than one billion people in Africa, Meso-America and many Asian countries (Shiferaw et al. 2011). Although a major portion of maize produced worldwide is used for consumption by livestock, yet maize serves as a vital source of proteins and calories to billions of people in developing countries (Gupta et al. 2013). At present, the developed world uses more maize than the developing world, but forecasts indicate that by the year 2050, the demand for maize in the developing countries will double (Rosegrant et al. 2009). White maize lacks carotenoids in the endosperm due to the presence of recessive $y 1$ or phytoene synthase (psyl), the key gene that controls the first step in the carotenoid biosynthesis pathway (Buckner et al. 1990). Whereas, the yellow/orange kernel maize with dominant $Y 1$ contains several carotenoid isoforms, including carotenes ( $\alpha$-carotene and $\beta$-carotene) and xanthophylls ( $\beta$-cryptoxanthin, zeaxanthin and lutein) (Buckner et al. 1990). Active PSY1 or Y1 allele is involved in the condensation of two geranyl geranyl pyrophosphate (GGPP) to form phytoene, which is then converted to lycopene by four desaturation reactions, mediated by phytoene desaturase ( $p d s)$ and zeta-carotene desaturase ( $z d s)$. Lycopene is further cyclized by $\varepsilon$ - and/or $\beta$-cyclase to give rise to $\alpha$ - and $\beta$-carotene that are subsequently hydroxylated by carotene hydroxylase and modified to form lutein, $\beta$-cryptoxanthin and zeaxanthin (Aluru et al. 2008). All these components in different proportions impart varying shades of yellow/orange colour to the maize kernel. Thus, by manipulation of the genes in the biosynthesis pathway, specific carotenoids can be increased in the maize kernel. Though various interventions like 'food fortification', 'supplementation' and 'dietary diversification' have been tried worldwide to alleviate micronutrient deficiencies, none of them had been found to be viable in the long run (Tanumihardjo et al. 2007). On the other hand, development of micronutrientenriched staple plant foods through plant breeding, a process referred to as "biofortification", holds promise for sustainable and cost-effective food-based solutions to combat micronutrient deficiencies (Pfeiffer and McClafferty 2007). Biofortified crops would also serve as the logical vehicle for providing micronutrients in pure form in the diets (Bouis and Welch 2010).

Information pertaining to the extent of variation for kernel carotenoids among diverse maize germplasm and the effect of environment on the performance of the genotypes, if any, assume tremendous significance to formulate an effective breeding strategy. Understanding the relationship among the different carotenoid components is equally important to hasten the pace of improvement to obtain maximum health benefits. Besides, understanding the association between kernel colour and the carotenoid components may further facilitate breeders for large-scale phenotyping for specific carotenoids, through 
avoiding the costly, laborious and time consuming high performance liquid chromatography (HPLC). Intensive efforts are currently being undertaken to develop maize inbreds enriched with carotenoids especially provitamin A (Babu et al. 2013; Gupta et al. 2013; Frano et al. 2014). Though some reports are available on variability of carotenoids in maize germplasm especially those adapted to Indian conditions, however, they are based on variability of total carotenoids estimated through colorimetric methods (Mishra and Singh 2010; Tiwari et al. 2012; Sivaranjani et al. 2013, 2014). Information regarding comprehensive analyses on components of carotenoids using precision-based HPLC methods, and their relationships among exotic and indigenous inbreds is lacking for designing suitable breeding strategy. We report here the genetic variation for kernel carotenoids among Indian- and CIMMYT-based maize germplasm, the effect of environment on the expression of kernel carotenoids, and the relationships among different carotenoids and with kernel colour.

\section{Materials and Methods}

\section{Plant material}

A diverse panel of 95 inbreds (panel I) from India- and CIMMYT-origin (exotic-tropical) having significant variation for kernel colour (ranging from pale yellow to deep orange) was selected. Of them, 55 inbreds were selected from different maize breeding centres of India that included, (i) 27 inbreds (MGU-) developed at Maize Genetics Unit, ICARIndian Agricultural Research Institute (IARI), New Delhi; (ii) eight inbreds (V-) from ICAR-Vivekananda Parvatiya Krishi Anusandhan Sansthan (VPKAS), Almora; (iii) six inbreds (LM-) from Punjab Agricultural University (PAU), Ludhiana; (iv) four inbreds (DMR-) developed by ICAR-Directorate of Maize Research (DMR), New Delhi; (v) four inbred lines (BAJIM-) developed at CSK-HPKV, Hill Agricultural Research and Extension Centre (HAREC), Bajaura; (vi) four inbreds (HKI-) from CCS-Haryana Agricultural University (CCS-HAU), Karnal; and (vii) two inbreds (NAI-) from UAS-Nagenahalli Research Centre, Karnataka. Six inbred lines (CML-) from CIMMYT, Mexico and set of 34 inbreds (HP-) developed under the CIMMYT-HarvestPlus programme, was also included in the present study. All these inbred lines were evaluated under randomised complete block design (RCBD) with two replications at three locations of India viz. (i) IARI

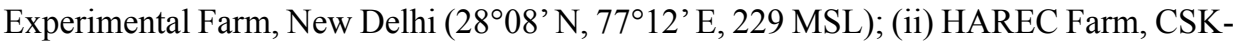

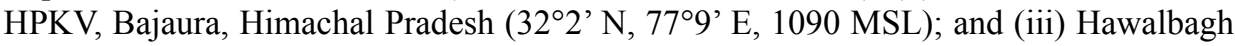

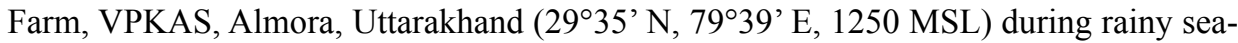
son (June-October), 2010. The inbreds were grown in $3 \mathrm{~m}$ row having spacing of $75 \mathrm{~cm}$ and plant to plant spacing of $20 \mathrm{~cm}$.

Further, a new set of 10 inbred lines (HP-) (panel II) having crtRB1 favourable allele, developed under the CIMMYT-Maize HarvestPlus programme were also evaluated in the rainy season of 2010 and 2011 under unreplicated trial at IARI Experimental Farm, New Delhi. Recommended cultural practices were followed to raise a good crop and each entry was self-pollinated to avoid any possible contamination from foreign pollen. Self-polli- 
nated ears from each entry were harvested separately; seeds were shelled under shade and stored in darkness at $4{ }^{\circ} \mathrm{C}$ until carotenoid extraction and quantification, as the carotenoids are affected by high temperature and light (Quackenbush 1963).

\section{Carotenoid extraction and quantification}

Extraction of carotenoids from finely ground kernels was carried out under dark conditions as per the procedure described by Kurilich and Juvick (1999). A $20 \mu$ l volume of each sample was manually injected into the Water Alliance HPLC System (Waters Chromatography, Milford, MA) attached with a photodiode array detector (PDA). YMC carotenoid $\mathrm{C}_{30}$ column $(5 \mu \mathrm{m}, 4.6 \times 250 \mathrm{~mm}$; Waters Chromatography, Milford, MA) was used to estimate the individual carotenoid components. The HPLC components include e2695 separation module and the 2996 photodiode array detector and the system was operated with Empower 2 Software (Waters Corporation). The mobile phase consisted of metha-

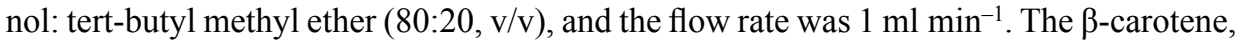
$\beta$-cryptoxanthin, lutein and zeaxanthin peaks were detected at $450 \mathrm{~nm}$ with $1.2 \mathrm{~nm}$ wavelength resolutions. Six dilutions of each carotenoid standard (SIGMA chemicals, USA) were used to make the standard curve; and concentration of various carotenoids in each sample was estimated by standard regression with external standards. The concentration of provitamin A carotenoids was calculated by adding the amount of $\beta$-carotene and onehalf of the amount of $\beta$-cryptoxanthin, while concentration of non-provitamin A carotenoids was computed by adding the value of lutein and zeaxanthin (Pixley et al. 2011). Total carotenoids were computed by summing the value of lutein, zeaxanthin, $\beta$-cryptoxanthin and $\beta$-carotene.

\section{Statistical analyses}

Analyses of variance (ANOVA) for lutein, zeaxanthin, $\beta$-cryptoxanthin and $\beta$-carotene across locations were calculated by considering inbred lines as fixed effects, and replications and locations as random effects using PROC MIXED of SAS (SAS Institute, 2005). Heritability (in broad sense) and genetic advance were estimated using the mean data of the genotypes across three locations (Singh and Chaudhary 1985). Pearson's simple correlation coefficients between pairs of carotenoid components and with kernel colour were computed using Windows-MS Office Excel, 2007. Inbreds of panel I was visually scored for their kernel colour as dark orange, orange, yellow and pale yellow, and was correlated with the various carotenoids viz., lutein, zeaxanthin, $\beta$-cryptoxanthin and $\beta$-carotene. Inbreds of panel II inbreds were not scored for kernel colour owing to low variability. 


\section{Results}

\section{Genetic variability for kernel carotenoids}

A set of 95 maize inbred lines (panel I) with diverse genetic background was surveyed for variability of kernel carotenoids. ANOVA revealed significant variation for lutein (1.3$11.3 \mu \mathrm{g} / \mathrm{g})$, zeaxanthin $(1.7-20.0 \mu \mathrm{g} / \mathrm{g}), \beta$-cryptoxanthin $(0.1-3.3 \mu \mathrm{g} / \mathrm{g})$ and $\beta$-carotene $(0.0-1.8 \mu \mathrm{g} / \mathrm{g})$ across locations. Pooled ANOVA further revealed significant effect of location for lutein, zeaxanthin and $\beta$-cryptoxanthin, but the same was not significant for $\beta$-carotene. However, variation due to location represented less than $1 \%$ of the total variation for all carotenoids (Table 1 ). Genotype $\times$ location interactions were significant for all the carotenoids, but accounts for $0.9-7.3 \%$ of the total variation. Whereas, the differences among genotypes accounted for the major proportion (92-99\% of the total variance across carotenoid components), suggesting that genotypes contributed more to total variation as compared to locations and genotype $\times$ location effects (Table 1). Broad sense heritability was high for all the carotenoids, ranging from $90.5 \%$ ( $\beta$-carotene) to $98.9 \%$ (zeaxanthin). Further, high genetic advance varied from $75.6 \%$ (lutein) to $110.9 \%$ $(\beta$-carotene).

Table 1. Mean sum of squares from the pooled ANOVA for different carotenoids among 95 genotypes (panel I) across three locations

\begin{tabular}{|l|r|c|c|c|c|}
\hline \multirow{2}{*}{ Sources of Variation } & \multirow{2}{*}{ df } & \multicolumn{4}{|c|}{ Mean sum of squares } \\
\cline { 3 - 6 } & & Lutein & Zeaxanthin & $\beta$-cryptoxanthin & $\beta$-carotene \\
\hline Genotype & 94 & $23.27^{* *}$ & $97.77^{* *}$ & $2.66^{* *}$ & $0.40^{* *}$ \\
Replication & 1 & $0.07^{*}$ & $0.82^{* *}$ & $0.02 * *$ & 0.00 \\
Location & 2 & $1.41^{* *}$ & $2.99^{* *}$ & $0.08^{* *}$ & 0.00 \\
Genotype $\times$ Location & 188 & $0.26^{* *}$ & $0.44^{* *}$ & $0.09 * *$ & $0.01 * *$ \\
Error & 284 & 0.01 & 0.01 & 0.00 & 0.00 \\
Total & 569 & & & & \\
\hline
\end{tabular}

df - degrees of freedom; $* * *$ indicates significance at $P \leq 0.05$ and 0.01 , respectively.

The study also revealed that non-provitamin A carotenoids had the major share (88\%) than the carotenoids with provitamin A activity (12\%) across genotypes in panel I. Of them, zeaxanthin was the predominant carotenoid $(53 \%)$, followed by lutein $(35 \%)$, $\beta$-cryptoxanthin (9\%) and $\beta$-carotene (3\%). The mean lutein concentration was $5.3 \mu \mathrm{g} / \mathrm{g}$, while the same for zeaxanthin was $7.8 \mu \mathrm{g} / \mathrm{g}$. The inbreds HP180-25 $(11.3 \mu \mathrm{g} / \mathrm{g}), \mathrm{DM}-$ RQPM58 (10.0 $\mu \mathrm{g} / \mathrm{g})$, CML161 $(10.0 \mu \mathrm{g} / \mathrm{g})$ were found promising for lutein, while CML161 (20.0 $\mu \mathrm{g} / \mathrm{g})$, HP19-33 (19.5 $\mu \mathrm{g} / \mathrm{g})$, DMRQPM58 (18.5 $\mu \mathrm{g} / \mathrm{g})$ and MGUDMRIL66 $(16.9 \mu \mathrm{g} / \mathrm{g})$ were identified with high zeaxanthin (Table 2$)$. Inbreds of panel I were found to be low in $\beta$-cryptoxanthin (mean: $1.3 \mu \mathrm{g} / \mathrm{g}$ ) and $\beta$-carotene (mean: $0.5 \mu \mathrm{g} / \mathrm{g}$ ) (Table 2). 

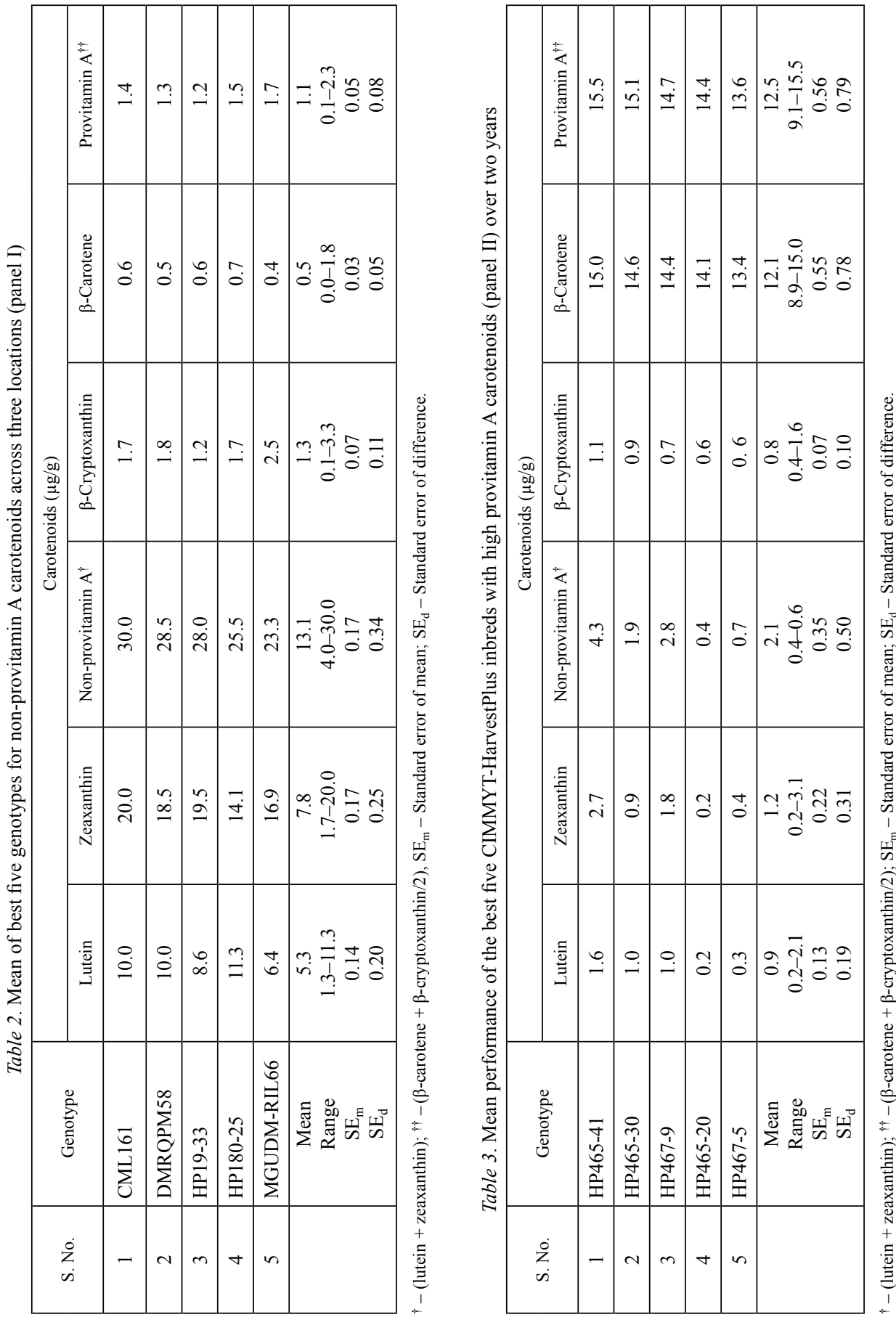
In panel II comprising CIMMYT-HarvestPlus genotypes having favourable allele of crtRB1, $\beta$-carotene was the predominant $(81 \%)$ carotenoid followed by zeaxanthin $(8 \%)$, lutein $(6 \%)$ and $\beta$-cryptoxanthin (5\%). In contrast to panel I, lutein (mean: $0.9 \mu \mathrm{g} / \mathrm{g}$ ), zeaxanthin $(1.2 \mu \mathrm{g} / \mathrm{g})$ and $\beta$-cryptoxanthin $(0.8 \mu \mathrm{g} / \mathrm{g})$ were low, while $\beta$-carotene $(12.1$ $\mu \mathrm{g} / \mathrm{g}$ ) was high. Based on the mean performance over two years, CIMMYT-HarvestPlus genotypes viz. HP465-41 and HP465-30 recorded more than $15 \mu \mathrm{g} / \mathrm{g}$ of provitamin A, the target level set by HarvestPlus to meet the recommended dietary allowance. Inbreds with high provitamin A ranked similar for $\beta$-carotene as well, for example, the best-inbred lines HP465-41 and HP465-30 had the highest concentration of provitamin A $(15.5 \mu \mathrm{g} / \mathrm{g}$ and $15.1 \mu \mathrm{g} / \mathrm{g})$ and also $\beta$-carotene $(15.0 \mu \mathrm{g} / \mathrm{g}$ and $14.6 \mu \mathrm{g} / \mathrm{g})$. Promising inbreds (HP46541, HP465-30, HP467-9, HP465-20 and HP467-5) with $>13.5 \mu \mathrm{g} / \mathrm{g}$ of provitamin A showing potential for use in breeding programme were identified in the study (Table 3 ).

\section{Correlation among various carotenoids and kernel colour}

The correlations between lutein and zeaxanthin, which are typically the predominant carotenoids observed in panel $\mathrm{I}$, were positive $(\mathrm{r}=0.53)$. However, lutein showed no correlation with $\beta$-carotene and $\beta$-cryptoxanthin. Zeaxanthin was positively correlated with $\beta$-cryptoxanthin $(\mathrm{r}=0.48)$ but not with $\beta$-carotene. In contrast, strong positive correlations were observed between lutein and zeaxanthin $(r=0.97)$, lutein and $\beta$-cryptoxanthin $(\mathrm{r}=0.90)$ and, zeaxanthin and $\beta$-cryptoxanthin $(\mathrm{r}=0.83)$ among inbreds of panel II. Interestingly, no correlation was observed between $\beta$-carotene and $\beta$-cryptoxanthin in both the inbred panels, even though the first one serves as precursor for later in the pathway. The study also showed that $\beta$-carotene, the major provitamin A carotenoid did not show correlation $(r=0.04)$ with variation in kernel colour. In contrast, kernel colour was positively correlated with lutein $(\mathrm{r}=0.25)$, zeaxanthin $(\mathrm{r}=0.47), \beta$-cryptoxanthin $(\mathrm{r}=0.44)$ and total carotenoids $(\mathrm{r}=0.47)$.

\section{Discussion}

The study revealed wide genetic variation for the kernel carotenoids viz. lutein, zeaxanthin and $\beta$-carotene across locations and panels. However, $\beta$-cryptoxanthin showed low variation in both the panel of inbreds. The components of variance indicated that the kernel carotenoid variability was largely due to the genotypic variance that suggests that carotenoids are highly amenable to genetic improvement (Wong et al. 2004; Chander et al. 2008). High heritability and genetic advance for all the carotenoids further suggested that selection for high concentration of various carotenoids would effectively respond to selection. $\beta$-carotene, has maximum genetic advance, showing the potential to biofortify maize for provitamin A through breeding approaches.

Pooled ANOVA showed variation due to location and genotype $\times$ location interaction represented a small fraction of the total variation of each of the carotenoids than the variation caused by genotypes. Similar results of low effect of location on carotenoid concentration were earlier reported in tropical inbred lines (Menkir et al. 2008), tropical open- 
pollinated varieties (Menkir and Maziya-Dixon 2004), temperate inbred lines (Kurilich and Juvik 1999) and hybrids (Egesel et al. 2003). These results thus indicate that genotypes grown at different environments may not have major changes in concentration of carotenoids and are generally consistent across environments. It may thus be possible that genotypes with high specific carotenoids developed at one location can be used across different maize growing zones.

The genetic variation for various carotenoids among traditional maize inbreds (panel I) showed zeaxanthin and lutein were the most predominant carotenoids. The concentration of provitamin A carotenoids among the genotypes was very less and the maximum provitamin A concentration observed was $2.3 \mu \mathrm{g} / \mathrm{g}$. Earlier, we have reported the same low range of kernel $\beta$-carotene using the same set of genotypes (Vignesh et al. 2012). Chander et al. (2008) also observed a similar trend of variation while evaluating a set of Chinese germplasm, and found less provitamin A concentration and more of lutein and zeaxanthin. The carotenes ( $\alpha$ - and $\beta$-carotene) are the intermediates in the carotenoid biosynthesis pathway, leading to the more synthesis of non-provitamin A (lutein and zeaxanthin), which is why maize kernels generally have limited provitamin A despite being rich in other carotenoids (Vallabhaneni et al. 2009). This study clearly showed that the conventionally available inbreds of both indigenous- and exotic-origin possess less provitamin A carotenoids and are rich source of antioxidants to humans (Olson 1989; Fraser and Bramley 2004).

Cardiovascular diseases are the leading causes of deaths worldwide (Mendis et al. 2011) and the intake of food rich in antioxidants reduce the risk of cardiovascular disease in humans (Dauchet et al. 2009). Further, inbreds with enhanced lutein and zeaxanthin can be potentially exploited for developing hybrids for poultry industry. Consumers generally prefer yellow-orange egg yolk as compared to off-white yolk (Lokaewmanee et al. 2010; Liu et al. 2012) and poultry industry often utilize extracts from petals of marigold flower containing high xanthophylls like lutein and zeaxanthin as egg colorant in feed, as chicken has a natural ability to deposit these molecules into their egg yolks (Galobart et al. 2004; Lokaewmanee et al. 2010). Thus, inbreds with high lutein and zeaxanthin identified in the study can be used in developing hybrids specifically for poultry industry, the major consumer of maize production in Asia. Further, demand for maize in Asia is expected to increase rapidly over the next few decades, driven largely by the growing income and changing dietary habits (mainly increased poultry and pork consumption) that require more maize as feed (Prasanna et al. 2010).

The inbreds (panel II) developed under CIMMYT-HarvestPlus maize biofortification programme were also evaluated to explore the possibilities of using them in the Indian maize breeding programme. In contrast to the results from the panel I, the concentration of $\beta$-carotene was much higher $(8.8-14.9 \mu \mathrm{g} / \mathrm{g})$ as compared to other carotenoids. This marked difference is due to the presence of allelic variation in the crtRB1 ( $\beta$-carotene hydroxylase) gene among the genotypes studied, in which the favourable allele increases the concentration of $\beta$-carotene by preventing its further hydroxylation to $\beta$-cryptoxanthin and zeaxanthin in the carotenoid biosynthesis pathway (Yan et al. 2010). Vitamin A deficiency (VAD) results in visual impairment and higher morbidity as well as mortality in at 
least 190 million pre-school children and 19 million pregnant women, mostly in Africa and South Asia (WHO 2009). It also causes low resistance to infectious diseases and accounts for about $70 \%$ of childhood deaths across the world (Black et al. 2008). Inbreds thus identified with high $\beta$-carotene $(\sim 15 \mu \mathrm{g} / \mathrm{g})$ would be useful in developing provitamin A enriched hybrids to alleviate vitamin A deficiency (VAD) worldwide (Zhang et al. 2012; Babu et al. 2013).

The results obtained from correlation analyses are as per the regulation of carotenoid biosynthesis by different genes in the pathway (DellaPenna and Pogson 2006). Moderately positive correlation between the major carotenoids in panel I viz. lutein and zeaxanthin, suggests the possibility of simultaneous improvement of both the antioxidants. Since, $\beta$-cryptoxanthin is the precursor of zeaxanthin; it is not surprising that zeaxanthin was correlated with $\beta$-cryptoxanthin (Howitt and Pogson 2006). Interestingly, $\beta$-carotene did not show any correlation with $\beta$-cryptoxanthin and zeaxanthin, even though the first one serves as precursor for the next two in the pathway. In contrast, strong positive correlations were observed among lutein, zeaxanthin and $\beta$-cryptoxanthin in the CIMMYTHarvestPlus $\beta$-carotene rich inbreds (panel II). This could be due to genetic nature of the experimental material, where all the genotypes were purposefully bred for favourable allele of $\operatorname{crtRB} 1$ gene, which blocks the hydroxylation of $\beta$-carotene to $\beta$-cryptoxanthin and zeaxanthin; and $\alpha$-carotene to lutein. These results are in agreement with the earlier reports (Kurilich and Juvik 1999; Menkir et al. 2008). Thus, selection for simultaneous increase in the levels of various carotenoids may be possible by selecting favourable alleles regulating different steps in carotenoid biosynthesis pathway.

Positive correlation of kernel colour with lutein, zeaxanthin and total carotenoids further indicated that selection of deep orange kernel genotypes generally would help in selecting higher non-provitamin A carotenoids. Tiwari et al. (2012) and Sivaranjani et al. (2013) also observed positive correlation between kernel colour and total carotenoids. However, the present investigation revealed that kernel colour was an unpredictable indicator for $\beta$-carotene, thereby suggesting that visual selection based on kernel colour will mislead in selecting provitamin A-rich genotypes (Harjes et al. 2008). Carotenoid profiling using HPLC to assess the concentration of $\beta$-carotene is expensive and time consuming. Thus selection based on the markers for favourable alleles of genes causing $\beta$-carotene enhancement in the pathway will be an effective approach for developing provitamin Arich maize genotypes (Yan et al. 2010; Babu et al. 2013) to alleviate VAD worldwide.

The present investigation demonstrates ample scope to enhance lutein and zeaxanthin (non-provitamin A carotenoids) and $\beta$-carotene (provitamin A carotenoid) in maize kernel. Stable nature of kernel carotenoids over locations coupled with high heritability offers enormous possibility to enhance these nutritionally important carotenoids through molecular crop breeding. Promising inbreds for non-provitamin A carotenoids identified here can be used for developing productive hybrids, which will serve as potential source of dietary antioxidants for human beings and poultry feed for imparting deep orange colour in egg yolk. CIMMYT-HarvestPlus inbreds with high $\beta$-carotene can be used as potential donor to increase the levels of provitamin A carotenoids in tropical-adapted Indian maize. Since selection based on kernel colour is not reliable for screening for high 
$\beta$-carotene, the present investigation emphasizes that selection based on gene-based markers for the favourable allele of $\operatorname{crtRB} 1$ gene causing $\beta$-carotene enhancement will be more effective and largely benefit the breeding for provitamin A-rich maize. Finally, these findings will help in biofortification of maize to provide micronutrients to human beings as well as livestock.

\section{Acknowledgements}

MV sincerely acknowledges the Indian Council of Agricultural Research (ICAR) for providing Senior Research Fellowship for his doctoral research. The financial support from Department of Biotechnology (DBT) under the project 'Development of micronutrient enriched maize through molecular breeding' (SAN No.102/IFD/SAN/4455/2011-2012) is gratefully acknowledged. The authors thank Dr. Kevin Pixley (CIMMYT-HarvestPlus Programme) for providing $\beta$-carotene rich lines used in the study. We also thank the breeders from AICMIP, India for sharing the inbred lines.

\section{References}

Aluru, M., Xu, Y., Guo, R., Wang, Z., Li, S., White, W., Wang, K., Roderme, S. 2008. Generation of transgenic maize with enhanced provitamin A content. J. Exp. Bot. 59:3551-3562.

Babu, R., Rojas, N.P., Gao, S., Yan, J., Pixley, K. 2013. Validation of the effects of molecular marker polymorphisms in $l c y E$ and $c r t R B 1$ on provitamin A concentrations for 26 tropical maize populations. Theor. Appl. Genet. 126:389-399.

Black, R.E., Allen, L.H., Bhutta, Z.A., Caulfield, L.E., de Onis, M., Ezzati, M., Mathers, C., Rivera, J., Maternal Child Under Nutrition Study Group. 2008. Maternal and child under nutrition: global and regional exposures and health consequences. Lancet 371:243-260.

Bouis, H.E., Welch, R.M. 2010. Biofortification - a sustainable agricultural strategy for reducing micronutrient malnutrition in the global South. Crop Sci. 50:S20-S32.

Buckner, B., Kelson, T.L., Robertson, D.S. 1990. Cloning of the $y 1$ locus of maize, a gene involved in the biosynthesis of carotenoids. Plant Cell 2:867-876.

Chander, S., Meng, Y., Zhang, Y., Yan, J., Li, J. 2008. Comparison of nutritional traits variability in selected eighty-seven inbreds from Chinese maize (Zea mays L.) germplasm. J. Agric. Food Chem. 56:6506-6511.

Dauchet, L., Amouyel, P., Dallongeville, J. 2009. Fruits, vegetables and coronary heart disease. Nat. Rev. Cardiol. 6:599-608.

DellaPenna, D., Pogson, B.J. 2006. Vitamin synthesis in plants: Tocopherols and carotenoids. Ann. Rev. Plant Biol. 57:711-738.

Egesel, C.O., Wong, J.C., Lambert, R.J., Rocheford, T.R. 2003. Combining ability of maize inbreds for carotenoids and tocopherols. Crop Sci. 43:818-823.

Frano, M.R.L., de Moura, F.F., Boy, E., Lonnerdal, B., Burri, B.J. 2014. Bioavailability of iron, zinc, and provitamin A in biofortified staple crops. Nut. Rev. 72:289-307.

Fraser, B.D., Bramley, P.M. 2004. The biosynthesis and nutritional uses of carotenoids. Progress in Lipid Res. 43:228-265.

Galobart, J., Sala, R., Rincon-Carruyo, X., Manzanilla, E.G., Vila, B., Gasa, J. 2004. Egg yolk color as affected by saponification of different natural pigmenting sources. J. Appl. Poult. Res. 13:328-334.

Gupta, H.S., Babu, R., Agrawal, P.K., Mahajan, V., Hossain, F., Nepolean, T. 2013. Accelerated development of quality protein maize hybrid through marker-assisted introgression of opaque-2 allele. Plant Breeding 132:77-82. 
Harjes, C.E., Rocheford, T.R., Bai, L., Brutnell, T.P., Kandianis, C.B., Sowinski, S.G., Stapleton, A.E., Vallabhaneni, R., Williams, M., Wurtzel, E.T., Yan, J., Buckler, E.S. 2008. Natural genetic variation in lycopene epsilon cyclase tapped for maize biofortification. Science 319:330-333.

Hess, S.Y., Thurnham, D.I., Hurrell, R.F. 2005. Influence of provitamin A carotenoids on iron, zinc, and vitamin A status. HarvestPlus Technical Monograph 6. HarvestPlus. Washington, DC, USA. 28 p.

Howitt, C.A., Pogson, B.J. 2006. Carotenoid accumulation and functions in seeds and non-green tissues. Plant, Cell Env. 29:435-445.

Johnson, M.P., Havaux, M., Triantaphylides, C., Ksas, B., Pascal, A.A., Robert, B., Davison, P.A., Ruban, A.V., Horton, P. 2007. Elevated zeaxanthin bound to oligomeric LHCII enhances the resistance of Arabidopsis to photooxidative stress by a lipid-protective, antioxidant mechanism. J. Biol. Chem. 282:22605-22618.

Kurilich, A., Juvik, J. 1999. Quantification of carotenoid and tocopherol antioxidants in Zea mays. J. Agric. Food Chem. 47:1948-1955.

Liu, Y.Q., Davis, C.R., Schmaelzle, S.T., Rocheford, T., Cook, M.E., Tanumihardjo, S.A. 2012. $\beta$-Cryptoxanthin biofortified maize (Zea mays) increases $\beta$-cryptoxanthin concentration and enhances the color of chicken egg yolk. Poultry Sci. 91:432-438.

Lokaewmanee, K., Yamauchi, K., Tsutomu, K., Saito, K. 2010. Effects on egg yolk color of paprika or paprika combined with marigold flower extracts. Ital. J. Anim. Sci. 9:356-359.

Mendis, S., Lindholm, L.H., Anderson, S.G., Alwan, A., Koju, R., Onwubere, B.J., Kayani, A.M., Abeysinghe, N., Duneas, A., Tabagari, S., Fan, W., Sarraf-Zadegan, N., Nordet, P., Whitworth, J., Heagerty, A. 2011. Total cardiovascular risk approach to improve efficiency of cardiovascular prevention in resource constrain settings. J. Clin. Epidemiol. 64:1451-1462.

Menkir, A., Liu, W., White, W.S., Maziya-Dixon, B., Rocheford, T. 2008. Carotenoid diversity in tropicaladapted yellow maize inbred lines. Food Chem. 109:521-529.

Menkir, A., Maziya-Dixon, B. 2004. Influence of genotype and environment on $\beta$-carotene content on tropical yellow endosperm maize genotypes. Maydica 49:313-318.

Mishra, P., Singh, N.K. 2010. Spectrophotometric and TLC based characterization of kernel carotenoids in short duration maize. Maydica 55:95-100.

Nambara, E., Marion-Poll, A. 2005. Abscisic acid biosynthesis and catabolism. Ann. Rev. Plant Biol. 56:165185.

Olson, J.A. 1989. Biological actions of carotenoids. J. of Nutrition 119:94-95.

Pfeiffer, W.H., McClafferty, B. 2007. HarvestPlus: Breeding crops for better nutrition. Crop Sci. 47:S88-S105.

Pixley, K.V., Palacios, N., Glahn, R.P. 2011. The usefulness of iron bioavailability as a target trait for breeding maize (Zea mays L.) with enhanced nutritional value. Field Crops Res. 123:153-160.

Prasanna, B.M., Pixley, K.V., Warburton, M., Xie, C. 2010. Molecular marker-assisted breeding for maize improvement in Asia. Mol. Breed. 26:339-356.

Quackenbush, F.W. 1963. Corn carotenoids: effects of temperature and moisture on losses during storage. Cereal Chem. 40:266-269.

SAS Institute Inc. 2005. SAS/Genetics TM 9.1.3 User's Guide. SAS Institute Inc. Cary, NC, USA.

Rosegrant, M.R., Ringler, C., Sulser, T.B., Ewing, M., Palazzo, A., Zhu, T. 2009. Agriculture and Food Security under Global Change: Prospects for 2025/2050. IFPRI. Washington, D.C., USA.

Shiferaw, B., Prasanna, B.M., Hellin, J., Banziger, M. 2011. Crops that feed the world 6. Past successes and future challenges to the role played by maize in global food security. Food Security 3:307-327.

Singh, R.K., Chaudhary, B.D. 1985. Biometrical methods in quantitative genetic analysis, Kalyani Publishers. New Delhi, India.

Sivaranjani, R., Prasanna, B.M., Hossain, F., Santha, I.M. 2013. Genetic variability for total carotenoid concentration in selected maize inbred lines. Indian J. Agr. Sci. 83:431-436.

Sivaranjani, R., Santha, I.M., Pandey, N., Vishwakarma, A.K., Nepolean, T., Hossain, F. 2014. Microsatellitebased genetic diversity in selected exotic and indigenous maize (Zea mays L.) inbred lines differing in total kernel carotenoids. Indian J. Genet. 74:34-41.

Tanumihardjo, S.A., Anderson, C., Kaufer-Horwitz, M., Bode, L., Emenaker, N.J., Haqq, A.M., Satia, J.A., Silver, H., Stadler, D.D. 2007. Poverty, obesity and malnutrition: an international perspective recognizing the paradox. J. Am. Diet. Assoc. 107:1966-1972. 
Tiwari, A., Prasanna, B.M., Hossain, F., Guruprasad, K.N. 2012. Analysis of genetic variability for kernel carotenoid concentration in selected maize inbred lines. Indian J. Genet. 72:1-6.

Vallabhaneni, R., Gallagher, C.E., Licciardello, N., Cuttriss, A.J., Quinlan, R.F., Wurtzel, E.T. 2009. Metabolite sorting of a germplasm collection reveals the hydroxylase3 locus as a new target for maize provitamin: A biofortification. Plant Physiol. 151:1635-1645.

Vignesh, M., Hossain, F., Nepolean, T., Saha, S., Agrawal, P.K., Guleria, S.K., Prasanna, B.M., Gupta, H.S. 2012. Genetic variability for kernel $\beta$-carotene and utilization of crtRB1 3'TE gene for biofortification in maize (Zea mays L.). Indian J. Genet. 72:189-194.

WHO 2009. Global prevalence of vitamin A deficiency in populations at risk 1995-2005. (http://www.who.int/ nutrition/publications/ micronutrients/vitamin A deficiency)

Wong, J.C., Lambert, R.J., Wurtzel, E.T., Rocheford, T.R. 2004. QTL and candidate genes phytoene synthase and $\zeta$-carotene desaturase associated with the accumulation of carotenoids in maize. Theor. Appl. Genet. 108:349-359.

Yan, J., Kandianis, B.C., Harjes, E.C., Bai, L., Kim, H.E., Yang, X., Skinner, D.J., Fu, Z., Mitchell, S., Li, Q., Fernandez, G.S.M., Zaharoeva, M., Babu, R., Fu, Y., Palacios, N., Li, J., DellaPenna, D., Brutnell, T., Buckler, S.E., Warburton, L.M., Rocheford, T. 2010. Rare genetic variation at Zea mays crtRB1 increases beta carotene in maize grain. Nat. Genet. 42:322-327.

Zhang, X., Pfeiffer, W.H., Palacios-Rojas, N., Babu, R., Bouis, H., Wang, J. 2012. Probability of success of breeding strategies for improving provitamin A content in maize. Theor. Appl. Genet. 125:235-246. 